OPEN ACCESS

Edited by:

Peter Brossart,

University of Bonn, Germany

Reviewed by:

Hyun-Sung Lee,

Baylor College of Medicine,

United States

Farrah Kheradmand,

Baylor College of Medicine,

United States

Sebastian Marwitz,

Research Center Borstel (LG),

Germany

*Correspondence:

Guangsuo Wang

wgswy01@163.com

Chang Chen

chenthoracic@163.com

Hanjie Li

hj.li@siat.ac.cn

${ }^{\dagger}$ These authors have contributed equally to this work

Specialty section:

This article was submitted to

Cancer Immunity and Immunotherapy,

a section of the journal

Frontiers in Oncology

Received: 14 June 2021 Accepted: 08 November 2021 Published: 03 January 2022

Citation:

Chen W-W, Liu W, Li Y, Wang J, Ren $Y$, Wang $G$, Chen $C$ and $L i H$ (2022) Deciphering the ImmuneTumor Interplay During Early-Stage Lung Cancer Development via Single-Cell Technology.

Front. Oncol. 11:716042. doi: 10.3389/fonc.2021.716042

\section{Deciphering the Immune-Tumor Interplay During Early-Stage Lung Cancer Development via Single-Cell Technology}

\author{
Wei-Wei Chen ${ }^{1 \dagger}$, Wei Liu ${ }^{2 \dagger}$, Yingze $\mathrm{Li}^{3 \dagger}$, Jun Wang ${ }^{2 \dagger}$, Yijiu Ren ${ }^{3}$, Guangsuo Wang ${ }^{4 *}$, \\ Chang $\mathrm{Chen}^{3 *}$ and Hanjie $\mathrm{Li}^{2 *}$ \\ ${ }^{1}$ Department of Clinical Oncology, University of Hong Kong, Hong Kong, Hong Kong SAR, China, ${ }^{2}$ CAS Key Laboratory of \\ Quantitative Engineering Biology, Shenzhen Institute of Synthetic Biology, Shenzhen Institutes of Advanced Technology, \\ Chinese Academy of Sciences, Shenzhen, China, ${ }^{3}$ Department of Thoracic Surgery, Shanghai Pulmonary Hospital, Tongji \\ University School of Medicine, Shanghai, China, ${ }^{4}$ Department of Thoracic Surgery, Shenzhen People's Hospital, The Second \\ Clinical Medical College, Jinan University, The First Affiliated Hospital, Southern University of Science and Technology, \\ Shenzhen, China
}

Lung cancer is the leading cause of cancer-related death worldwide. Cancer immunotherapy has shown great success in treating advanced-stage lung cancer but has yet been used to treat early-stage lung cancer, mostly due to lack of understanding of the tumor immune microenvironment in early-stage lung cancer. The immune system could both constrain and promote tumorigenesis in a process termed immune editing that can be divided into three phases, namely, elimination, equilibrium, and escape. Current understanding of the immune response toward tumor is mainly on the "escape" phase when the tumor is clinically detectable. The detailed mechanism by which tumor progenitor lesions was modulated by the immune system during early stage of lung cancer development remains elusive. The advent of single-cell sequencing technology enables tumor immunologists to address those fundamental questions. In this perspective, we will summarize our current understanding and big gaps about the immune response during early lung tumorigenesis. We will then present the state of the art of single-cell technology and then envision how single-cell technology could be used to address those questions. Advances in the understanding of the immune response and its dynamics during malignant transformation of pre-malignant lesion will shed light on how malignant cells interact with the immune system and evolve under immune selection. Such knowledge could then contribute to the development of precision and early intervention strategies toward lung malignancy.

Keywords: tumorigenesis, early-stage lung cancer, single-cell sequencing technology, immune-editing, immune evasion, tumor immunology 


\section{INTRODUCTION}

As a life-threatening disease, lung cancer was estimated to cause more than 1.8 million deaths per year all over the world, with a 5 -year survival rate of less than $20 \%$ (1). Based on the pathological type, lung cancer is divided into small cell lung cancer and non-small cell lung cancer (NSCLC), with the latter accounting for approximately $85 \%$ of the cases $(1,2)$. The histological subtypes of lung cancer are complex and highly various, which makes it challenging for the early diagnosis and treatment of lung cancer. Thus, accurate and comprehensive clinicopathological classification is critical in guiding the clinical treatment and predicting the prognosis of lung cancer (3-5). In 2016, the International Association for the Study of Lung Cancer (IASLC) proposed the 8th edition of TNM staging. Lung adenocarcinoma (LUAD) and its precursors range from atypical adenomatous hyperplasia, invasive adenocarcinoma in situ, micro-invasive adenocarcinoma, to eventually invasive lung adenocarcinoma (6). If lung cancer can be identified and treated at an early stage, before angiogenesis and invasion, patients have a greater chance of better disease control rate and survival rate.

Although many therapies, including chemotherapy, radiosurgery, targeted therapy, and immunotherapy, have been applied for lung cancer treatment, the 5-year survival rate is only $50 \%$ for patients with early-stage lung cancer (7). Surgery accounts for the primary first-line treatment for patients with early-stage lung cancer (8). However, patients with early-stage lung cancer may be diagnosed as multiple lesions, which occurs in $30 \%-50 \%$ of early-stage lung cancer (9). Besides, multiple lesions may occur simultaneously or successively in patients with lung cancer (10). There are great limitations in the radical and surgical treatment for multifocal early lung adenocarcinoma, while chemotherapy and targeted therapy cannot ameliorate the dilemmas, either. Thus, it is urgent to develop a novel therapy regimen for patients with early-stage lung cancer. With the recent development of tumor immunology, immunotherapy has provided new options for lung cancer patients (11-13). The emergence of immune checkpoint inhibitors has opened a new era of cancer therapy. Anti-PD-1/PD-L1 immunotherapy, an immune normalization therapy, selectively reinvigorates the anti-tumor immune responses in the tumor microenvironment (TME) with fewer immune-related adverse events $(14,15)$. Immunotherapy combined with surgery shows impressive clinical benefits in early-stage resectable NSCLC (16). Numerous ongoing clinical trials of immunotherapies and the novel combination therapies suggest that immunotherapies can be an optimal treatment strategy for unresectable early-stage NSCLC (14). However, the 5-year survival rate in NSCLC patients after combined surgery with immunotherapy treatment is still not ideal $(17,18)$. On the other hand, patients with the same TNM stage showed different prognosis outcomes after immunotherapy (19). Therefore, despite its success, it is still pressing to disentangle the complicated interactions between the immune system and tumor progression for developing novel and more effective strategies for the immune diagnosis and immunotherapies of lung cancer (20-22).
Profiling of the molecular states of all cell types within the lung tissue is currently revolutionizing the discovery of the mechanisms of lung cancer development (23) and can provide plentiful novel insights into the immune-tumor interplay in the early stage of lung cancer (24). The single-cell sequencing technologies in transcriptomics, genomics, epigenomics, proteomics, metabolomics, and spatial information have revolutionized biomedical research. The application of these tools enables the multidimensional study of organs, from cell atlas profiling, cell fate determination, cell-cell interaction to spatial construction $(25,26)$. Single-cell multi-omics have also emerged in recent years. All aspects of the cell, including a full history of its molecular states, spatial positions, and environmental interactions can be examined at the level of single cell by multimodal technologies and integrated computational methods (27). These methods demonstrated the power of simultaneously characterizing multiple levels of the immune response, which may boost our understanding of the underlying molecular mechanisms on how tumor evolves, and therefore contribute to the early detection and treatment of lung cancer by aiding the rational design of innovative diagnostic and personalized management approaches for patients $(28,29)$ (Table 1). Here, we discuss recent progress in employing multidimensional single-cell sequencing technologies to investigate the initiation and development processes of the premalignant lesion into lung cancer.

\section{GENERAL TUMOR EVOLUTION PROCESS AND UNIQUE CHARACTERISTICS IN THE EARLY STAGE OF LUNG CANCER}

The development of lung cancer is a multistep process defined by spatiotemporal interactions between heterogeneous cell types, including the malignant, immune, and stromal cells in a complex ecosystem (48). The functional diversity of immune cells is especially critical for the generation of the different regulator and effector responses required to safeguard the host against cancer, while survived tumor cells evolve to actively evade immune surveillance (49). The innate and adaptive arms of our immune system act as a complementary network of selfdefense against the early progression from normal to malignant (50). Despite the fact that the immune system can identify and destroy nascent tumor cells, it can also be hijacked to promote tumor initiation and progression $(51,52)$. The dual anti-tumor and pro-tumor roles of immunity are referred to as cancer immunoediting (50). Immunoediting consists of three processes that function to control and shape cancer development either independently or in sequence. In the elimination phase, innate and the adaptive immune systems recognize transformed cells and destroy them, resulting in a return to normal physiological tissue (53). However, if antitumor immunity fails to eliminate transformed cells (also known as immunoselection), survived tumor cells may enter into the equilibrium phase, when the adaptive immunity prevents tumor outgrowth (53). Then, these cell variants may eventually 
TABLE 1 | Important discoveries of single-cell technology in the evolution of early-stage lung cancer.

\begin{tabular}{|c|c|c|c|c|}
\hline $\begin{array}{l}\text { Fields of Lung } \\
\text { Cancer }\end{array}$ & Years & $\begin{array}{l}\text { Pathological } \\
\text { Type }\end{array}$ & Conclusions & Referenc \\
\hline \multirow[t]{4}{*}{ Tumor Heterogeneity } & 2015 & LUAD & Identified intratumoral and intertumoral heterogeneity and the correlation with prognosis & (30) \\
\hline & 2017 & SCLC & Proposed a novel mutation profile and expression characteristics of SCLC & (31) \\
\hline & 2020 & LUAD & Detected heterogeneity at the molecular level in each tumor and stromal cells of GGN more effectively & (32) \\
\hline & 2021 & LUAD & Characterized the heterogenetic of tumor cells, immune cells, and stromal cells in SSN lesions & (33) \\
\hline Evolution and & 2014 & NSCLC & Detected the differential expression in metastasis-associated cancer initiation cells & (34) \\
\hline \multirow[t]{3}{*}{ Metastasis } & 2020 & LUAD & Revealed the progression of lung adenocarcinoma mainly depends on tumor cell reprogramming & (35) \\
\hline & 2020 & LUAD & $\begin{array}{l}\text { Discovered a cluster of tumor cells with high plasticity and the potential to transform into different } \\
\text { states }\end{array}$ & (36) \\
\hline & 2021 & LUAD & Analyzed unravel cell populations, states, and phenotypes in the spatial and ecologic evolution & $(37)$ \\
\hline \multirow[t]{2}{*}{ Tumor Metabolic } & 2017 & LUAD & Found a new metabolic phenotype of lung cancer and provide a theoretical framework & (38) \\
\hline & 2019 & LUAD & Analyzed different expressed genes of single malignant cells with different metabolic phenotypes & (39) \\
\hline \multirow[t]{2}{*}{$\begin{array}{l}\text { Lung Cancer } \\
\text { Treatment }\end{array}$} & 2015 & LUAD (cell line) & $\begin{array}{l}\text { Revealed different expression patterns of individual cells induced by molecular targeted drug therapy } \\
\text { resistance }\end{array}$ & $(40)$ \\
\hline & 2021 & LUAD & Characterized the different tumor microenvironment and provided prognostic information & $(41)$ \\
\hline Tumor & 2017 & LUAD & Analyzed the early immune cells, especially the innate immune cells and their molecular profiles & $(42)$ \\
\hline \multirow[t]{5}{*}{ Microenvironment } & 2018 & NSCLC & Showed the landscape of stroma and immune cells of NSCLC & (43) \\
\hline & 2018 & NSCLC & Explored the heterogeneity and characteristics of T cells in TME & (44) \\
\hline & 2020 & NSCLC & Reveals the diversity of B cells in the early stage of non-small cell lung cancer & $(45)$ \\
\hline & 2021 & NSCLC & Verified the enrichment of different macrophage subtypes in lung cancer & (46) \\
\hline & 2021 & LUAD & Characterize shifts in the TME from early to advanced lung cancer & (47) \\
\hline
\end{tabular}

LUAD, lung cancer adenocarcinoma; NSCLC, non-small cell lung cancer; SCLC, small cell lung cancer; GGN, ground glass nodule; SSN, subsolid nodule; CNV, copy number variation.

acquire further mutations that help them evade immune surveillance, and progress to clinically detectable malignancies in the escape phase (54).

The immune responses in the process of lung cancer evolution gradually transit from immune activation to immunosuppression, characterized by decreased T-cell clonotypes, increased infiltration of regulatory $\mathrm{T}$ cells, and the reduced infiltration of cytotoxic $\mathrm{T}$ cells and anti-tumor helper $\mathrm{T}$ cells (55). Meanwhile, the driver mutations, chromosomal copy number aberrations, and abnormal epigenetic events in tumor cells work together to influence host immune responses (56). These results reveal that the early development of lung cancer is a continuous and gradual process modulated by the immuneediting mechanism (Figure 1). However, it was demonstrated that the precancerous mutated cells in some early-stage lung cancer patients were already able to suppress the immune system and escape the immune surveillance before the invasive stage, which is contradictive to the supposed elimination phase of immune-editing theory $(57,58)$. Thus, the developmental process in the early stage of lung cancer does not have to go through the three immune-editing phases in sequence. Some early mutations can confer the tumor cells with strong immunosuppressive capability, paralyzing anti-tumor immune responses to early tumor development (59). Consequently, those tumor cells might skip the elimination and equilibrium phase and jump into the "escape" phase. Besides, the highly heterogeneous tumor immune microenvironments of individual patients also limit the wide applicability of the immune-editing theory. Furthermore, the detailed regulatory pathways that determine the phase transition during the



FIGURE 1 | The lung cancer tumorigenesis in the early stage of lung cancer is depicted. In the pre-lesion, the immune cells dominate the microenvironment and eliminate the malignant cells by inducing the cell death. In the immune equilibrium phase, the malignant cells become quiescent under the control of the activated immune cells. As the disease progress, the malignant cells escape the immune surveillance. 
immune-editing process remain elusive. Conventional strategies using bulk cell populations are unable to fully delineate the various cell types and states engaged in the immune process toward malignancy, impeding further the investigation and precise interventional therapy (60). By contrast, single-cell techniques can classify the individual cells, gain into the multidimensional interactions between the tumor and the immune system, characterize the variations in their molecular profiles and developmental processes, and then contribute to the development of novel and practical strategies for the immune diagnosis and intervention of early-stage lung cancer (61) (Table 2). Here, we will highlight current findings and the potential application of single-cell technology in deciphering the evolution process of early stage of lung cancer.

\section{APPLICATION OF SINGLE-CELL TECHNOLOGIES IN THE EARLY STAGE OF LUNG CANCER}

\section{Single-Cell RNA Sequencing in the Early Stage of Lung Cancer}

Single-cell RNA sequencing (ScRNA-seq) technologies allow the dissection of the gene expression at single-cell resolution, revolutionizing transcriptomic studies from various aspects such as cell clustering, trajectory inference, differential expression calling, alternative splicing, allelic expression, and gene regulatory network reconstruction (64). These techniques have paved the way for the discovery of previously unknown cell types and subtypes in the normal and diseased lung, especially facilitating the study of rare cells (65). Furthermore, scRNA-seq can characterize immune cells and tumor cells in an unbiased manner at the same time (66).

The analysis of the single-cell transcriptomes of the seven stages of the mouse lung tumors, from pre-neoplastic hyperplasia to adenocarcinoma, found that the diversity of transcriptional states in the tumor and immune cells increased over time (36). In human subjects, a scRNA-seq study of 16 subsolid nodules samples and 6 adjacent normal lung tissues revealed that the cytotoxic natural killer T cells were dominant in the TME of subsolid nodules, and the malignant cells in the subsolid nodules underwent strong metabolic reprogramming and immune stress (67). Besides, a scRNA-seq analysis of ground-glass nodules (GGNs) demonstrated that the proliferation of the cancer cells was inhibited, and the immune cells were more activated in the GGN, compared with the activated proliferation of the cancer cells and the suppressive immune cells in the solid adenocarcinoma (32). A study of a total of 16 subsolid nodules (SSNs) samples from 16 treatment-naive patients provided single-cell transcriptomic profiling of SSN and their TME and indicated that SSNs exhibited more indolent biological behaviors than solid LUAD, that cytotoxic natural killer/T cells dominated in the TME of SSN, that malignant cells in SSN underwent enhanced immune stress, and that the subtype composition of endothelial cells

TABLE 2 | Summary of advantages and disadvantages of current single-cell sequencing platforms in studying the evolution of early-stage LUAD.

\begin{tabular}{|c|c|c|c|c|c|}
\hline \multirow{2}{*}{$\begin{array}{l}\text { Molecular } \\
\text { level } \\
\text { Method }\end{array}$} & \multicolumn{2}{|c|}{ mRNA } & \multirow{2}{*}{$\begin{array}{l}\text { mRNA+ Protemoics } \\
\text { CITE-seq, Mars-seq }\end{array}$} & \multirow{2}{*}{$\begin{array}{c}\text { Genome } \\
\text { SNS, SCl-seq }\end{array}$} & \multirow{2}{*}{$\begin{array}{l}\text { Epigenome } \\
\text { sciATAC-seq; } \\
\text { scATAC-seq }\end{array}$} \\
\hline & Smart-seq2 & Droplet-based scRNA-seq & & & \\
\hline Indications & $\begin{array}{l}\text { Alternative splicing of } \\
\text { genes }\end{array}$ & $\begin{array}{l}\text { Differential gene expression } \\
\text { calling } \\
\text { Allelic expression of genes } \\
\text { Gene regulatory network } \\
\text { reconstruction dynamic } \\
\text { changes and heterogeneity } \\
\text { cell percentage and subtypes } \\
\text { Cell trajectory inference }\end{array}$ & $\begin{array}{l}\text { Analysis of targeted } \\
\text { populations; phenotypic } \\
\text { classifications based on } \\
\text { surface protein and } \\
\text { transcriptomic }\end{array}$ & $\begin{array}{l}\text { Recording of the interaction } \\
\text { between mutant tumor cells } \\
\text { and the immune cells' } \\
\text { behaviors } \\
\text { The cell clonal evolution }\end{array}$ & $\begin{array}{l}\text { Epigenetic biomarkers for } \\
\text { early cancer diagonstic and } \\
\text { epigentic regulation of genes }\end{array}$ \\
\hline Advantages & $\begin{array}{l}\text { Full-length transrcpit } \\
\text { to find the mutation } \\
\text { and splicing } \\
\text { alteration of tumor } \\
\text { cell }\end{array}$ & $\begin{array}{l}\text { Available commercial kits } \\
\text { High content to identify } \\
\text { different types and } \\
\text { heterogeneity } \\
\text { Sufficient quantity and quality } \\
\text { of gene detections }\end{array}$ & $\begin{array}{l}\text { Rare cell-type dicovery and } \\
\text { more presice in cell } \\
\text { phenotype identification }\end{array}$ & $\begin{array}{l}\text { Genetic deterministic genes in } \\
\text { governing the emergence and } \\
\text { maintenance of heterogeneity } \\
\text { and colonel evolution }\end{array}$ & $\begin{array}{l}\text { Investigation of regulatory } \\
\text { state transitions and } \\
\text { chromatin- modifying } \\
\text { proteins in malignant } \\
\text { transformation }\end{array}$ \\
\hline Disadvantages & $\begin{array}{l}\text { Pathology misdiagnosi } \\
\text { Hard to identify the line } \\
\text { and rare cell types } \\
\text { Hard to characterize th } \\
\text { and initiation tumor site } \\
\text { Require live cells and } r\end{array}$ & $\begin{array}{l}\text { is in early stage of lung cancer } \\
\text { eage tracing of cell phenotypes } \\
\text { ne clonality, inter-patient ITH, } \\
\text { e } \\
\text { high sample quality }\end{array}$ & $\begin{array}{l}\text { High cost; difficult to } \\
\text { standarized in different labs }\end{array}$ & $\begin{array}{l}\text { Missing information about } \\
\text { transcriptional heterogeneity } \\
\text { during tumor progression }\end{array}$ & $\begin{array}{l}\text { Difficult to determine how } \\
\text { cells navigate these } \\
\text { regulatory transitions toward } \\
\text { malignant }\end{array}$ \\
\hline Reference & $\begin{array}{l}\text { Marjanovic, N.D., et } \\
\text { al. (36) }\end{array}$ & $(33,43,45,47,62)$ & $\begin{array}{l}\text { Lavin, Y., et al. (35); LaFave, } \\
\text { L.M., et al. (42); Leader, } \\
\text { Grout et al. (62) }\end{array}$ & Rooney, Shukla et al. (63) & $\begin{array}{l}\text { LaFave, L.M., et al. (35); } \\
\text { Marjanovic, N.D., et al. (36) }\end{array}$ \\
\hline
\end{tabular}

NSCLC, non-small cell lung cancer; Smart-seq2, Switching Mechanism At the end of the 5'-end of the RNA Transcript; scRNA, single-cell RNA sequencing; SNS, single-nucleus sequencing; SCl-seq, single-cell combinatorial indexed sequencing; SCATAC-seq, Single-cell sequencing assay for transposase- accessible chromatin; ITH, intratumor heterogeneity; CITE-seq, cellular Indexing of Transcriptomes and Epitopes by Sequencing; Mars-seq, massively parallel single-cell RNA-Seq. 
was more like that in normal lung samples in SSN (62). ScRNA-seq has unmasked the complexity and heterogeneity of tumor-immune interplay during the transformation from pre-malignant lesions to cancerous damage.

ScRNA-seq analysis also helps elucidate the detailed interactions between tumor cells and immune cells in the early stage of lung cancer. A multiscale single-cell profiling of 35 early-stage NSCLC lesions found that a key cellular module consisting of $P D C D 1^{+}$ $\mathrm{CXCL}_{13}{ }^{+}$activated $\mathrm{T}$ cells, $\mathrm{IgG}^{+}$plasma cells, and $S P P 1^{+}$ macrophages, closely associated with evasion of lung cancer cells (62). A scRNA-seq analysis of human and mouse lung tumors unveiled that tissue-resident macrophages accumulated close to tumor cells promoted epithelial-mesenchymal transition and invasiveness, and induced a potent regulatory $\mathrm{T}$ cell response that protected tumor cells from adaptive immunity during early tumor formation (46). Consistently, Lavin et al. also demonstrated that Treg and non-functional $\mathrm{T}$ cells were enriched but cytolytic natural killer cells were excluded in the early LUAD lesions (42). Furthermore, Guo, Zhang et al. showed that there was a significant proportion of inter-tissue effector $\mathrm{T}$ cells with a highly migratory nature and that a high ratio of "pre-exhausted" to exhausted $\mathrm{T}$ cells was associated with a better prognosis of lung adenocarcinoma $(42,44)$. In addition, a study of seven stage-I/II LUAD samples harboring EGFR mutations and five tumor-adjacent lung tissues revealed that the adenocarcinoma cells were characterized by activated cell proliferation and antigen presentation to immune cells (68).

By comparing malignant lung samples with the non-malignant counterparts, scRNA-seq also uncovered the different and plastic interaction patterns between immune cells and normal cells or malignant cells. Lambrechts et al. identified some heterogeneous sub-subpopulations in stromal cells and the transcription factors that regulate their heterogeneity in the early LUAD patients by scRNA-seq (43). ScRNA-seq analysis of 10 normal lung tissues and 10 fresh LUAD tissues found that the TME was composed of cancer-associated myofibroblasts, exhausted $\mathrm{CD}^{+} \mathrm{T}$ cells, proinflammatory monocyte-derived macrophages, plasmacytoid dendritic cells, myeloid dendritic cells, anti-inflammatory monocyte-derived macrophages, normal-like myofibroblasts, NK cells, and conventional T cells (69). Multi-region of five early-stage LUADs and 14 multi-region normal lung tissues found that the Treg $^{+}$cells are increased in normal tissues with proximity to LUAD and the signatures and fractions of cytotoxic CD8+ T cells, antigen-presenting macrophages, and inflammatory dendritic cells were decreased (37).

ScRNA also unveiled the different characteristics of tumorimmune interplays between early-stage and advanced-stage LUAD. Compared with the early-stage LUAD, scRNA-seq demonstrated the naive-like $B$ cells decreased in advanced NSCLC, and their lower number was associated with poor prognosis (45). Based on scRNA-seq data of 29 lung samples of different developmental stages, Chen, Huang et al. found that advanced malignant cells exhibited a remarkably more complex TME and higher intratumor heterogeneity level than early malignant cells. In terms of immune cells, the proportions of $\mathrm{CD}^{+} /$cytotoxic $\mathrm{T}$ cells, Treg+ $\mathrm{T}$ cells, and follicular $\mathrm{B}$ cells remarkedly differed in early and advanced LUAD. Notably, the ligand-receptor analysis found that the GNAI2-DRD2 and C4BCD46 pairs were only detected in advanced LUAD, while COL3A1-MAG, HLA-C-SLC9C2, and COL2A1-MAG were uniquely expressed in early LUAD (47).

Collectively, scRNA-seq has helped characterize the cellular phenotypes of various immune and tumor cell types and reveal their interactions within the TME during the development of lung cancer. However, there are many limitations by now. One of the major challenges is the paucity of human patient samples available for scRNA-seq in the early stage of lung cancer. Further validation by alternative methods or larger patient cohorts is required (70). Furthermore, sample quality is a big issue because it is impossible to separate the LUAD featured with ground glass nodules from solid adenocarcinoma by pathological methods when studying the initiation of LUAD (45). Moreover, the scRNA-seq lacks the power to distinguish the ground glass opacification part and the solid part in the same LUAD, which is vital to identify the initiation site of the cellular activation module. Furthermore, it is difficult to interpret the evolution process of specific cells, identify cell phenotypes for lineage tracing, acquire cell surface antigens information, characterize the intratumor clonal heterogeneity and inter-patient clonal heterogeneity, and identify genomic alterations by scRNA-seq. Therefore, we will further discuss other single-cell techniques and their potential applications in the investigation of early-stage lung cancer development.

\section{Single-Cell Genome Sequencing in the Early Stage of Lung Cancer}

In the initiation of lung cancer, a single normal cell gradually evolves into a malignant tumor cell and forms distinct subpopulations, which then lead to intratumoral heterogeneity and clonal diversity by genomic alterations (71). Copy number variations or single-nucleotide variations in EGFR, RBM10, MET, $B R A F, K-R a s$, and TP53 were found to be functionally important in the evolution of lung cancer (72). The genome doubling and ongoing dynamic chromosomal instability in CDK4, FOXA1, and $B C L 11 A$ also resulted in the progression of lung cancer $(73,74)$. These genomic alterations are also present in early-stage lung cancer cells, determining their sensitivity to the immune cells and associating with immune cells' phenotypes (75). For example, patients harboring KRAS mutations displayed significantly lower levels of dysfunctional immune T-cell markers: PD-1 and TIM-3, in the tumors than those with wild-type KRAS, which indicated a suppressive immune microenvironment in EGFR-mutated tumors (76). Furthermore, it was found that the ADCY8, PIK3CA, and $C D K N 2 A$ mutations were associated with remarkedly decreased expression of the immune-inhibitory ligand: PD-L1 (77), which indicated an upregulated immune response in early-stage lung cancer patients with these gene mutations. McGranahan et al. demonstrated the positive association of high tumor mutation burdens with more activated $\mathrm{CD} 8^{+} \mathrm{T}$ cells and higher levels of $\mathrm{PD}$ L1 expression in early-stage NSCLC (78).

Although these results revealed the important roles of gene mutations in the early stage of lung cancer by interacting with 
the immune system, most of the results derived from the sequencing data of bulk tumor cells, which is difficult to unmask the deeper underlying genotypic and phenotypic heterogeneity that exists inter- and intra-tumors. Furthermore, the number of cells harboring the mutations and the zygosity of these mutations cannot be accurately assessed by bulk genome sequencing (79). Moreover, current findings were insufficient to clarify the interactions between the individual mutant tumor cells and the immune cells when the normal epithelial cells transformed to malignant cells (63). Meanwhile, it remains unclear how the components of adaptive immune system individually respond to the transformation at the genome level (80). Single-cell DNA sequencing may overcome these obstacles by detecting the founder mutations and sub-clonal mutations in tumor cells at a single-cell level (81). Further application of the newly developed single-genome technique, such as SNS-seq (singlenucleus sequencing), LIANT (single-cell whole-genome analyses by linear amplification via transposon insertion), and SCI-seq (single-cell combinatorial indexed sequencing) (82) may unravel the clonal relationship between different malignant cells and dissect the immune responses contributed by the genomic elements of the individual cells during the progression from pre-malignant lesion to advanced oncogenesis (83).

\section{Single-Cell Epigenome Sequencing in the Early Stage of Lung Cancer}

Cellular heterogeneity of individual cells within the tumorimmune ecosystem is displayed not only in the genome and transcriptome, but also in the epigenome. Epigenetic alterations, including DNA methylation, histone modifications, and noncoding RNA expression, have been reported to play an important role in the tumorigenesis of lung cancer $(84,85)$. At the epigenetic level, the histone $\mathrm{H} 3$ lysine 36 methyltransferase NSD3 could promote the development of lung squamous cell carcinoma (86). The DNA methyltransferase inhibitors and histone deacetylase inhibitors could reverse tumor immune evasion in NSCLC by modulating the T-cell exhaustion state towards the memory and effector T-cell phenotypes $(87,88)$. Besides, the antigen presentations of the immune cells are also altered by epigenetic modulations with the hypomethylating agents or histone deacetylase inhibitors (89). These findings demonstrated the vital roles of epigenetic regulation in cancer evolution. However, the detailed mechanisms of how these epigenetic events modulate the immunoediting process in specific cell types remain unclear during lung cancer early development.

Single-cell epigenome profiling methods include scATAC-seq (assay for transposase-accessible chromatin in single cells with sequencing), scCHIP-seq (single-cell chromatin immuneprecipitation followed by sequencing), sciHi-C (single-cell combinatorial indexed $\mathrm{Hi}-\mathrm{C}$ ), and scCUT\&Tag (single-cell cleavage under targets \& tagmentation) (90-93). ScATAC-seq can reveal the chromatin accessibility landscape that governs the transcriptional regulation in different cell populations (94).
Sn-m3C-seq (single-nucleus methyl-3C sequencing) can give information about chromatin organization and DNA methylation and distinguish the heterogeneous cell types (95). Smart-RRBS (single-cell methylome and transcriptome analysis) can detect the methylation status in the promoters of specific tumor suppressor genes and the overall number of hypermethylated genes, which increases with the neoplastic progression from hyperplasia to adenocarcinoma (96). A scATAC-seq analysis of the K-Ras+/LSLG12D;p53frt/frt (KP) mouse model found that the cancer cells were tightly regulated by the smarca4, which regulated the activity of the lung lineage SWI/SNF transcription factor and ultimately accelerated tumor progression (35). Using the KP mice and sciATAC-seq (combinatorial indexing to identify single cells without singlecell isolation for chromatin accessibility), LaFave, Kartha et al. also defined co-accessible regulatory programs and inferred key activating and repressive chromatin regulators of epigenetic changes in the tumor cells, including RUNX transcription factors (which are predictive biomarkers for the survival of LUAD patients) (35).

Together, these results demonstrated the power of single-cell epigenomics to identify regulatory programs and key biomarkers during tumor progression. Combined single-cell methods have also emerged to allow analyses of epigenetic-transcriptional correlations, thereby enabling detailed investigations of how epigenetic states modulate cell phenotypes and the immune editing process.

\section{Single-Cell Proteomics in the Early Stage of Lung Cancer}

Although single-cell transcriptomic, genomic, and epigenomic methods have been informative about gene expression and genome landscapes and have demonstrated vital basic research and clinical value in lung cancer, information on proteins is also important and necessary since proteins are the cellular workhorses (97). Methods of protein detection at the single-cell level include flow cytometry, Sc-MS (liquid chromatography mass spectrometry-based single-cell proteomics), ScoPE (isobaric labeling for single-cell proteomics), CyTOF (cytometry by timeof-flight), SCITO-seq (single-cell combinatorial indexed cytometry sequencing), CITE-seq (cellular indexing of transcriptomes and epitopes by sequencing), Mars-seq (massively parallel single-cell RNA-Seq), and SCPFC (single-cell phospho-specific flow cytometry) (98-100). Some of these methods can simultaneously measure multiple cellular proteins and RNA at the single-cell level.

Leader Grout et al. applied CITE-seq combining phenotypic classifications based on surface protein expression and transcriptomic profile, to characterize the cellular classification and increase our understanding of the immune cellular landscape in the mouse model of early-stage lung cancer (62). Lin et al. utilized SCPFC in the investigation of signaling network interactions and unraveled the dynamic changes of tyrosine phospho-Stat1 (pStat1) in lung cancer cells in a mouse model (101). More recently, Rahman et al. performed a CyTOF analysis of cell suspensions derived from tissues of early-stage LUAD 
after surgical resection. They found that high levels of cerium were specifically associated with a phenotypically distinct subset of lung macrophages that were most prevalent in noninvolved lung tissue, whereas tumor-associated macrophages had lower levels of cerium (99). The CyTOF combined with mars-seq2 fully characterized the immune landscape of early-stage LUAD and distinguished the immune changes driven by the tumor lesion from those driven by the lung tissue (42).

In sum, single-cell proteomics can add another dimension to clarify the substantial heterogeneity and complicated interaction among seemingly identical cells at the genome level, significantly contributing to the quantitative understanding of the developmental mechanisms of early-stage lung cancer.

\section{Single-Cell Metabolic Profiling in the Early Stage of Lung Cancer}

The metabolic reprogramming is fundamental to both cancer cells and responding immune cells during cancer development (102, 103). Moreover, metabolic heterogeneity and plasticity exist in diverse cells, especially in the immune cells responding to cancer cells (104-106). A recent finding indicated that lactate acid secreted by the glycolytic cancer cells favored the activation of the immune cells toward an immunosuppressive phenotype (107). In addition, the cancer cells could harness the metabolic by-products to induce the immune suppressive microenvironment (108).

The single-cell metabolomics field is at its very early stage at this moment. The sc-MS (single-cell metabolic profiling by mass cytometry) $(109,110)$ and the SCENITH (Flow CytometryBased Method to Functionally Profile Energy Metabolism with Single-Cell Resolution) were recently developed (111). These technologies could reveal global metabolic functions and determine complex and linked immune phenotypes in rare cell subpopulations $(112,113)$.

\section{Lineage Tracing Combined With Single-Cell Sequencing in the Early Stage of Lung Cancer}

Another long-standing quest is to understand the developmental origin and the cell fate determination of each cell within a tissue (114). Cell states are highly flexible and present multipotent characteristics before reaching differentiation destination. A comprehensive study of the molecular alterations during cell fate determination would be useful to better clarify those steps involved in the precancerous stage of lung tumor. Using the methods of lineage tracing with single-cell technology such as CellTaging (a combinatorial cell indexing approach), TracerSeq (transposon-based barcoding sequencing), scGESTALT (singlecell genome editing of synthetic target arrays for lineage tracing), and MEMOIR (memory by engineered mutagenesis with optical in situ readout), we can investigate an individual cell early and track the states of its clonal progeny at a later time point via sequencing of the inherited DNA sequences, or "barcodes" (115117). These methods offer an opportunity to integrate complementary information about both cell lineage and cell states into synthetical views of cell a differentiation destination and dynamic interactions between the tumor and immune cells
$(118,119)$. ScRNA-seq combined with lineage tracing allows simultaneous measurement of cell identity and developmental origin at single-cell resolution (119). Zepp et al. revealed that the transformation from the alveolar type 1 progenitor cells to alveolar type 2 cells in the mesenchymal alveolar niche of the lung is important for the tissue injury response by combining scRNA-seq and signaling lineage reporter system $(58,120)$. Furthermore, Wellenstein et al. tracked the fate determination process of immune cells in response to the antigens expressed specifically on the surface of nearby tumor cells during the immune editing process (121). Labeling cell subpopulations across the lung region by the Dre-Rox or Cre-LoxP recombination system together with single-cell sequencing technology has potential to be used for simultaneously investigating the reciprocal evolution of tumor cells and immune cells as well as their fate determinations in the lesion at the initial stage $(122,123)$.

Together, parallel advances in single-cell sequencing techniques and lineage tracing methods facilitate the mapping of the clonal relationships onto the tumor immune landscape and help decipher the crosstalk between the tumor and immune cells during the whole developmental process.

\section{Single-Cell Spatial Omics in the Early Stage of Lung Cancer}

Recent advances in spatially resolved methods allow us to achieve transcriptional cell-type classifications, map cellular spatial distributions in tissues, and reveal the intracellular and intercellular networks in lung tumors (124). Genome sequencing analyses of 25 spatially distinct regions of earlystage NSCLC found that the driver mutations displayed subclonal diversification in different regions, embodying the value of combining spatial information with sequencing data in deciphering the mechanism of the evolution of lung cancer cells (125). Many single-cell spatial transcriptomics combines spatial barcoding-based methods (ST, Visium, HDST, Slidesee, Naostring, GeoMx, DBiT-seq, and Zipcode) and imaging-based methods (osm-FISH, MERFISH, SeqFish, STARMAP, and FISSEQ) (126-128). These technologies may deepen our understanding of the functional organization of the tissue and the cellular and molecular mechanism on how cancer cells modify their surroundings to generate an immune suppressive microenvironment in the early-stage lung cancer (126-128). Indeed, single-cell spatial transcriptomics has already started to be used to delineate the precise landscape of the TME and the crosstalk between the tumor and immune cells at both cellular and sub-cellular levels (129). A spatial transcriptomics analysis of LUAD and LUSC samples has demonstrated the spatial gene expression atlas and spatial heterogeneity variation between LUAD and LUSC as well as differences in normal and cancerous regions (130).

The immune responses occurring in the early stage of lung cancer are mediated by not only the cell-cell interaction, but also the coordinated actions of a diverse set of cytokines (131). In the early stage of lung cancer, the majority of the cytokines consists 


\section{Single cell Omics}

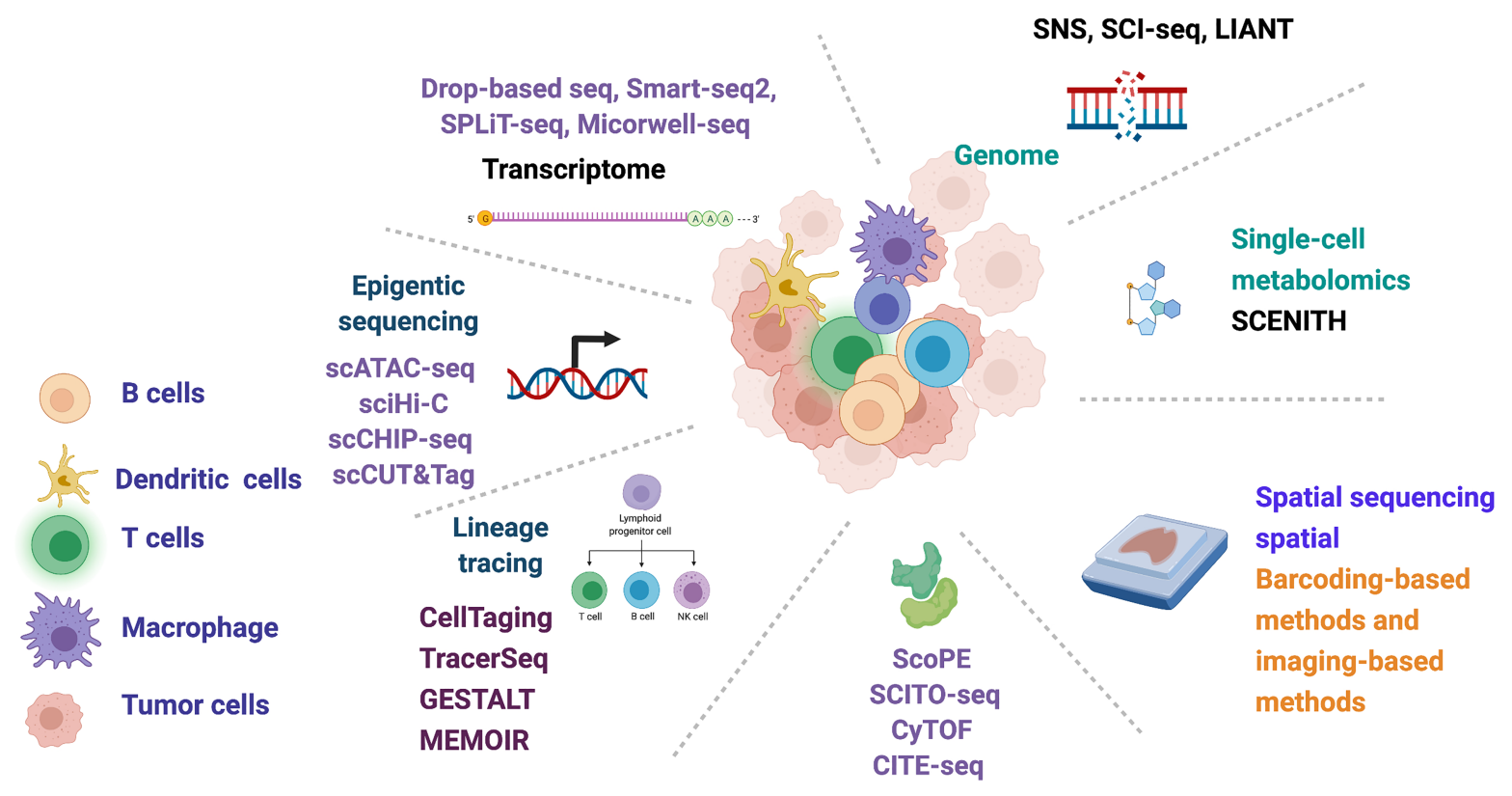

FIGURE 2 | Summary of current single-cell multi-omics technology that may be used in deciphering the early-stage lung cancer evolution.

of IFN- $\gamma$, IL-12, and TNF- $\alpha$, whereas the concentration of the pro-angiogenic cytokine VEGF is extremely low (132, 133). These cytokines are crucial for regulating the immune equilibrium. However, the spatial localization of tissue-resident immune or tumor cells producing specific modulatory cytokines remains elusive. The application of the spatial genomic sequencing method at the single-cell level can specifically identify the signaling interactions and communications between the immune and tumor cells in the early stage of lung cancer $(115,127)$. Together, analyzing single-cell gene expression in a spatially resolved context is critical for understanding the heterotypic interactions among the cells in the TME in the early stage of lung cancer.

\section{CONCLUSION AND PERSPECTIVE}

A comprehensive understanding of the tumor immune microenvironment is vital to treatment options and prognosis of lung cancer. Multi-omics simultaneous profiling of gene expression, genetic variation, epigenetic change, cell surface proteins, metabolic activities, and spatial information from the same single cell allows full and robust delineation of the developmental plasticity and immune-mediated pruning of the tumor cells from multiple dimensions during the early development of lung cancer (Figure 2).

The goal of tumor immunology research is to be able to manipulate the immune cells/molecules to prevent and treat cancer (134). A deeper understanding of the immune-tumor interplay during early-stage lung cancer by single-cell sequencing technology can help identify novel immunotherapy targets, determine which patients may benefit most from immunotherapy, and discover new mechanisms of resistance to immunotherapy (135).

In sum, our views of the applications of the multi-omics single-cell techniques in the early stage of lung cancer will contribute to broadening their application in relevant basic research and boosting the development of immunotherapy for early-stage lung cancer.

\section{AUTHOR CONTRIBUTIONS}

All authors critically wrote and revised the manuscript. All authors contributed to the article and approved the submitted version.

\section{FUNDING}

The research was supported by the National Key R\&D Program of China (2019YFA0906100 and 2020YFA0804100); the National Natural Science Foundation of China (32170919 and 92042305); Shanghai Pulmonary Hospital Innovation Team (FKCX1906); Shanghai Science and Technology Committee (20YF1441100, 20XD1403000, 18DZ2293400); Shenzhen Science and Technology Program (KQTD2016113015442590) and Natural Science Foundation of Guangdong (2021A1515010919). 


\section{REFERENCES}

1. Siegel RL, Miller KD, Jemal A. Cancer Statistics, 2020. CA Cancer J Clin (2020) 70(1):7-30. doi: 10.3322/caac.21590

2. Wei W, Zeng H, Zheng R, Zhang S, An L, Chen R, et al. Cancer Registration in China and its Role in Cancer Prevention and Control. Lancet Oncol (2020) 21(7):e342-9. doi: 10.1016/S1470-2045(20)30073-5

3. Owada-Ozaki Y, Muto S, Takagi H, Inoue T, Watanabe Y, Fukuhara M, et al. Prognostic Impact of Tumor Mutation Burden in Patients With Completely Resected Non-Small Cell Lung Cancer: Brief Report. J Thorac Oncol (2018) 13(8):1217-21. doi: 10.1016/j.jtho.2018.04.003

4. Tavernari D, Battistello E, Dheilly E, Petruzzella AS, Mina M, SordetDessimoz J, et al. Non-Genetic Evolution Drives Lung Adenocarcinoma Spatial Heterogeneity and Progression. Cancer Discov (2021) 11(6):1490507. doi: 10.1158/2159-8290.CD-20-1274

5. Sharma A, Merritt E, Hu X, Cruz A, Jiang C, Sarkodie H, et al. Non-Genetic Intra-Tumor Heterogeneity Is a Major Predictor of Phenotypic Heterogeneity and Ongoing Evolutionary Dynamics in Lung Tumors. Cell Rep (2019) 29(8):2164-2174 e5. doi: 10.1016/j.celrep.2019.10.045

6. Detterbeck FC, Boffa DJ, Kim AW, Tanoue LT. The Eighth Edition Lung Cancer Stage Classification. Chest (2017) 151(1):193-203. doi: 10.1016/ j.chest.2016.10.010

7. Gettinger S, Horn L, Jackman D, Spigel D, Antonia S, Hellmann M, et al. Five-Year Follow-Up of Nivolumab in Previously Treated Advanced NonSmall-Cell Lung Cancer: Results From the CA209-003 Study. J Clin Oncol (2018) 36(17):1675-84. doi: 10.1200/JCO.2017.77.0412

8. Manser R, Wright G, Hart D, Byrnes G, Campbell DA. Surgery for Early Stage Non-Small Cell Lung Cancer. Cochrane Database Syst Rev (2005) 2005 (1):Cd004699. doi: 10.1002/14651858.CD004699.pub2

9. Blandin Knight S, Crosbie PA, Balata H, Chudziak J, Hussell T, Dive C. Progress and Prospects of Early Detection in Lung Cancer. Open Biol (2017) 7(9):170070. doi: 10.1098/rsob.170070

10. Liu C, Li H, Xu K, Song S, He Y, Cai X, et al. Multiple Primary Lung Cancer Versus Intrapulmonary Metastatic Cancer: A Case of Multiple Pulmonary Nodules. Thorac Cancer (2019) 10(2):352-8. doi: 10.1111/1759-7714.12918

11. Riley RS, June CH, Langer R, Mitchell MJ. Delivery Technologies for Cancer Immunotherapy. Nat Rev Drug Discovery (2019) 18(3):175-96. doi: 10.1038/ s41573-018-0006-Z

12. Yang Y. Cancer Immunotherapy: Harnessing the Immune System to Battle Cancer. J Clin Invest (2015) 125(9):3335-7. doi: 10.1172/JCI83871

13. Ko EC, Raben D, Formenti SC. The Integration of Radiotherapy With Immunotherapy for the Treatment of Non-Small Cell Lung Cancer. Clin Cancer Res (2018) 24(23):5792-806. doi: 10.1158/1078-0432.CCR-17-3620

14. Rosner S, Reuss JE, Forde PM. PD-1 Blockade in Early-Stage Lung Cancer. Annu Rev Med (2019) 70:425-35. doi: 10.1146/annurev-med-050217-025205

15. Liu SY, Wu YL. Ongoing Clinical Trials of PD-1 and PD-L1 Inhibitors for Lung Cancer in China. J Hematol Oncol (2017) 10(1):136. doi: 10.1186/ s13045-017-0506-z

16. Forde PM, Chaft JE, Smith KN, Anagnostou V, Cottrell TR, Hellmann MD, et al. Neoadjuvant PD-1 Blockade in Resectable Lung Cancer. N Engl J Med (2018) 378(21):1976-86. doi: 10.1056/NEJMoa1716078

17. Hoy H, Lynch T, Beck M. Surgical Treatment of Lung Cancer. Crit Care Nurs Clin North Am (2019) 31(3):303-13. doi: 10.1016/j.cnc.2019.05.002

18. Ghysen K, Vansteenkiste J. Immunotherapy in Patients With Early Stage Resectable Nonsmall Cell Lung Cancer. Curr Opin Oncol (2019) 31(1):13-7. doi: $10.1097 / C C O .0000000000000497$

19. Walk EE, Yohe SL, Beckman A, Schade A, Zutter MM, Pfeifer J, et al. The Cancer Immunotherapy Biomarker Testing Landscape. Arch Pathol Lab Med (2020) 144(6):706-24. doi: 10.5858/arpa.2018-0584-CP

20. Gonzalez H, Hagerling C, Werb Z. Roles of the Immune System in Cancer: From Tumor Initiation to Metastatic Progression. Genes Dev (2018) 32(1920):1267-84. doi: 10.1101/gad.314617.118

21. O'Donnell JS, Teng MWL, Smyth MJ. Cancer Immunoediting and Resistance to T Cell-Based Immunotherapy. Nat Rev Clin Oncol (2019) 16 (3):151-67. doi: 10.1038/s41571-018-0142-8

22. Bruni D, Angell HK, Galon J. The Immune Contexture and Immunoscore in Cancer Prognosis and Therapeutic Efficacy. Nat Rev Cancer (2020) 20 (11):662-80. doi: 10.1038/s41568-020-0285-7
23. Zhang Y, Liu F. Multidimensional Single-Cell Analyses in Organ Development and Maintenance. Trends Cell Biol (2019) 29(6):477-86. doi: 10.1016/j.tcb.2019.02.006

24. Wu F, Fan J, He Y, Xiong A, Yu J, Li Y, et al. Single-Cell Profiling of Tumor Heterogeneity and the Microenvironment in Advanced Non-Small Cell Lung Cancer. Nat Commun (2021) 12(1):2540. doi: 10.1038/s41467-021-22801-0

25. Baslan T, Hicks J. Unravelling Biology and Shifting Paradigms in Cancer With Single-Cell Sequencing. Nat Rev Cancer (2017) 17(9):557-69. doi: $10.1038 /$ nrc. 2017.58

26. Gawad C, Koh W, Quake SR. Single-Cell Genome Sequencing: Current State of the Science. Nat Rev Genet (2016) 17(3):175-88. doi: 10.1038/nrg.2015.16

27. Hedlund E, Deng Q. Single-Cell RNA Sequencing: Technical Advancements and Biological Applications. Mol Aspects Med (2018) 59:36-46. doi: 10.1016/ j.mam.2017.07.003

28. Greenberg AK, Yee H, Rom WN. Preneoplastic Lesions of the Lung. Respir Res (2002) 3(1):20-0. doi: 10.1186/rr170

29. Klebe S, Henderson DW. Facts and Fiction: Premalignant Lesions of Lung Tissues. Pathology (2013) 45(3):305-15. doi: 10.1097/PAT.0b013e32835f45fd

30. Min JW, Kim WJ, Han JA, Jung YJ, Kim KT, Park WY, et al. Identification of Distinct Tumor Subpopulations in Lung Adenocarcinoma via Single-Cell RNASeq. PloS One (2015) 10(8):e0135817. doi: 10.1371/journal.pone.0135817

31. Xiong D, Pan J, Yin Y, Jiang H, Szabo E, Lubet RA, et al. Novel Mutational Landscapes and Expression Signatures of Lung Squamous Cell Carcinoma. Oncotarget (2018) 9(7):7424-41. doi: 10.18632/oncotarget.23716

32. Lu T, Yang X, Shi Y, Zhao M, Bi G, Liang J, et al. Single-Cell Transcriptome Atlas of Lung Adenocarcinoma Featured With Ground Glass Nodules. Cell Discov (2020) 6:69. doi: 10.1038/s41421-020-00200-x

33. Xing X, Yang F, Huang Q, Guo H, Li J, Qiu M, et al. Decoding the Multicellular Ecosystem of Lung Adenocarcinoma Manifested as Pulmonary Subsolid Nodules by Single-Cell RNA Sequencing. Sci $A d v$ (2021) 7(5):eabd9738. doi: 10.1126/sciadv.abd9738

34. Rothwell DG, Li Y, Ayub M, Tate C, Newton G, Hey Y, et al. Evaluation and Validation of a Robust Single Cell RNA-Amplification Protocol Through Transcriptional Profiling of Enriched Lung Cancer Initiating Cells. BMC Genomics (2014) 15:1129. doi: 10.1186/1471-2164-15-1129

35. LaFave LM, Kartha VK, Ma S, Meli K, Del Priore I, Lareau C, et al. Epigenomic State Transitions Characterize Tumor Progression in Mouse Lung Adenocarcinoma. Cancer Cell (2020) 38(2):212-.e13. doi: 10.1016/ j.ccell.2020.06.006

36. Marjanovic ND, Hofree M, Chan JE, Canner D, Wu K, Trakala M, et al. Emergence of a High-Plasticity Cell State During Lung Cancer Evolution. Cancer Cell (2020) 38(2):229-46.e13. doi: 10.1016/j.ccell.2020.06.012

37. Sinjab A, Han G, Treekitkarnmongkol W, Hara K, Brennan PM, Dang M, et al. Resolving the Spatial and Cellular Architecture of Lung Adenocarcinoma by Multiregion Single-Cell Sequencing. Cancer Discov (2021) 11(10):2506-23. doi: 10.1158/2159-8290.CD-20-1285

38. Yu L, Lu M, Jia D, Ma J, Ben-Jacob E, Levine H, et al. Modeling the Genetic Regulation of Cancer Metabolism: Interplay Between Glycolysis and Oxidative Phosphorylation. Cancer Res (2017) 77(7):1564-74. doi: 10.1158/0008-5472.CAN-16-2074

39. Li Z, Wang Z, Tang Y, Lu X, Chen J, Dong Y, et al. Liquid Biopsy-Based Single-Cell Metabolic Phenotyping of Lung Cancer Patients for Informative Diagnostics. Nat Commun (2019) 10(1):3856. doi: 10.1038/s41467-01911808-3

40. Suzuki A, Matsushima K, Makinoshima H, Sugano S, Kohno T, Tsuchihara K, et al. Single-Cell Analysis of Lung Adenocarcinoma Cell Lines Reveals Diverse Expression Patterns of Individual Cells Invoked by a Molecular Target Drug Treatment. Genome Biol (2015) 16:66. doi: 10.1186/s13059-015-0636-y

41. Kim M, Min YK, Jang J, Park H, Lee S, Lee CH. Single-Cell RNA Sequencing Reveals Distinct Cellular Factors for Response to Immunotherapy Targeting CD73 and PD-1 in Colorectal Cancer. J Immunother Cancer (2021) 9(7): e002503. doi: 10.1136/jitc-2021-002503

42. Lavin Y, Kobayashi S, Leader A, Amir E-AD, Elefant N, Bigenwald C, et al. Innate Immune Landscape in Early Lung Adenocarcinoma by Paired Single-Cell Analyses. Cell (2017) 169(4):750-65.e17. doi: 10.1016/j.cell.2017.04.014

43. Lambrechts D, Wauters E, Boeckx B, Aibar S, Nittner D, Burton O, et al. Phenotype Molding of Stromal Cells in the Lung Tumor Microenvironment. Nat Med (2018) 24(8):1277-89. doi: 10.1038/s41591-018-0096-5 
44. Guo X, Zhang Y, Zheng L, Zheng C, Song J, Zhang Q, et al. Global Characterization of T Cells in Non-Small-Cell Lung Cancer by Single-Cell Sequencing. Nat Med (2018) 24(7):978-85. doi: 10.1038/s41591-018-0045-3

45. Chen J, Tan Y, Sun F, Hou L, Zhang C, Ge T, et al. Single-Cell Transcriptome and Antigen-Immunoglobin Analysis Reveals the Diversity of B Cells in Non-Small Cell Lung Cancer. Genome Biol (2020) 21(1):152. doi: 10.1186/ s13059-020-02064-6

46. Casanova-Acebes M, Dalla E, Leader AM, LeBerichel J, Nikolic J, Morales $\mathrm{BM}$, et al. Tissue-Resident Macrophages Provide a Pro-Tumorigenic Niche to Early NSCLC Cells. Nature (2021) 595(7868):578-84. doi: 10.1038/ s41586-021-03651-8

47. Chen Z, Huang Y, Hu Z, Zhao M, Li M, Bi G, et al. Landscape and Dynamics of Single Tumor and Immune Cells in Early and Advanced-Stage Lung Adenocarcinoma. Clin Transl Med (2021) 11(3):e350. doi: 10.1002/ctm2.350

48. Nasim F, Sabath BF, Eapen GA. Lung Cancer. Med Clin North Am (2019) 103(3):463-73. doi: 10.1016/j.mcna.2018.12.006

49. Schreiber RD, Old LJ, Smyth MJ. Cancer Immunoediting: Integrating Immunity's Roles in Cancer Suppression and Promotion. Science (2011) 331(6024):1565-70. doi: 10.1126/science.1203486

50. Rosenthal R, Cadieux EL, Salgado R, Bakir MA, Moore DA, Hiley CT, et al. Neoantigen-Directed Immune Escape in Lung Cancer Evolution. Nature (2019) 567(7749):479-85. doi: 10.1038/s41586-019-1032-7

51. Vesely MD, Kershaw MH, Schreiber RD, Smyth MJ. Natural Innate and Adaptive Immunity to Cancer. Annu Rev Immunol (2011) 29:235-71. doi: 10.1146/annurev-immunol-031210-101324

52. Dunn GP, Old LJ, Schreiber RD. The Immunobiology of Cancer Immunosurveillance and Immunoediting. Immunity (2004) 21(2):137-48. doi: 10.1016/j.immuni.2004.07.017

53. Dunn GP, Bruce AT, Ikeda H, Old LJ, Schreiber RD. Cancer Immunoediting: From Immunosurveillance to Tumor Escape. Nat Immunol (2002) 3(11):991-8. doi: 10.1038/ni1102-991

54. Kunimasa K, Goto T. Immunosurveillance and Immunoediting of Lung Cancer: Current Perspectives and Challenges. Int J Mol Sci (2020) 21(2):597. doi: 10.3390/ijms21020597

55. Saab S, Zalzale H, Rahal Z, Khalifeh Y, Sinjab A, Kadara H. Insights Into Lung Cancer Immune-Based Biology, Prevention, and Treatment. Front Immunol (2020) 11(159). doi: 10.3389/fimmu.2020.00159

56. Dejima $\mathrm{H}, \mathrm{Hu} \mathrm{X}$, Chen $\mathrm{R}$, Zhang J, Zhang J. Immune Evolution From Preneoplasia to Invasive Lung Adenocarcinomas and Underlying Molecular Features. Nat Commun (2021) 12(1):2722. doi: 10.1038/s41467-021-22890-x

57. Singhal S, Stadanlick J, Annunziata MJ, Rao AS, Bhojnagarwala PS, O’Brien $S$, et al. Human Tumor-Associated Monocytes/Macrophages and Their Regulation of T Cell Responses in Early-Stage Lung Cancer. Sci Transl Med (2019) 11(479):eaat1500. doi: 10.1126/scitranslmed.aat1500

58. Vinay DS, Ryan EP, Pawelec G, Talib WH, Stagg J, Elkord E, et al. Immune Evasion in Cancer: Mechanistic Basis and Therapeutic Strategies. Semin Cancer Biol (2015) 35(Suppl):S185-98. doi: 10.1016/j.semcancer.2015.03.004

59. Zitvogel L, Tesniere A, Kroemer G. Cancer Despite Immunosurveillance: Immunoselection and Immunosubversion. Nat Rev Immunol (2006) 6 (10):715-27. doi: 10.1038/nri1936

60. Wiel C, Le Gal K, Ibrahim MX, Jahangir CA, Kashif M, Yao H, et al. BACH1 Stabilization by Antioxidants Stimulates Lung Cancer Metastasis. Cell (2019) 178(2):330-45.e22. doi: 10.1016/j.cell.2019.06.005

61. Seijo LM, Peled N, Ajona D, Boeri M, Field JK, Sozzi G, et al. Biomarkers in Lung Cancer Screening: Achievements, Promises, and Challenges. J Thorac Oncol (2019) 14(3):343-57. doi: 10.1016/j.jtho.2018.11.023

62. Leader AM, Grout JA, Chang C, Maier B, Tabachnikova A, Walker L, et al. CITEseq Analysis of Non-Small-Cell Lung Cancer Lesions Reveals an Axis of Immune Cell Activation Associated With Tumor Antigen Load and TP53 Mutations. Cold Spring Harbor Laboratory (2020).

63. Rooney MS, Shukla SA, Wu CJ, Getz G, Hacohen N. Molecular and Genetic Properties of Tumors Associated With Local Immune Cytolytic Activity. Cell (2015) 160(1-2):48-61. doi: 10.1016/j.cell.2014.12.033

64. Chen G, Ning B, Shi T. Single-Cell RNA-Seq Technologies and Related Computational Data Analysis. Front Genet (2019) 10:317. doi: 10.3389/ fgene.2019.00317

65. Schiller HB, Montoro DT, Simon LM, Rawlins EL, Meyer KB, Strunz M, et al. The Human Lung Cell Atlas: A High-Resolution Reference Map of the
Human Lung in Health and Disease. Am J Respir Cell Mol Biol (2019) 61 (1):31-41. doi: 10.1165/rcmb.2018-0416TR

66. Papalexi E, Satija R. Single-Cell RNA Sequencing to Explore Immune Cell Heterogeneity. Nat Rev Immunol (2018) 18(1):35-45. doi: 10.1038/ nri.2017.76

67. Reyfman PA, Walter JM, Joshi N, Anekalla KR, McQuattie-Pimentel AC, Chiu S, et al. Single-Cell Transcriptomic Analysis of Human Lung Provides Insights Into the Pathobiology of Pulmonary Fibrosis. Am J Respir Crit Care Med (2019) 199(12):1517-36. doi: 10.1164/rccm.201712-2410OC

68. He D, Wang D, Lu P, Yang N, Xue Z, Zhu X, et al. Single-Cell RNA Sequencing Reveals Heterogeneous Tumor and Immune Cell Populations in Early-Stage Lung Adenocarcinomas Harboring EGFR Mutations. Oncogene (2021) 40(2):355-68. doi: 10.1038/s41388-020-01528-0

69. Bischoff P, Trinks A, Obermayer B, Pett JP, Lehmann A, Jurmeister P, et al. Single-Cell RNA Sequencing Reveals Distinct Tumor Microenvironmental Patterns in Lung Adenocarcinoma. Oncogene (2021). doi: 10.1038/s41388021-02054-3

70. Batson J, Royer L, Webber J. Molecular Cross-Validation for Single-Cell RNA-Seq. bioRxiv (2019) 786269. doi: 10.1101/786269

71. McGranahan N, Swanton C. Clonal Heterogeneity and Tumor Evolution: Past, Present, and the Future. Cell (2017) 168(4):613-28. doi: 10.1016/ j.cell.2017.01.018

72. Reiniger L, Téglási V, Pipek O, Rojkó L, Glasz T, Vágvölgyi A, et al. Tumor Necrosis Correlates With PD-L1 and PD-1 Expression in Lung Adenocarcinoma. Acta Oncol (2019) 58(8):1087-94. doi: 10.1080/ 0284186X.2019.1598575

73. Kerr EM, Gaude E, Turrell FK, Frezza C, Martins CP. Mutant Kras Copy Number Defines Metabolic Reprogramming and Therapeutic Susceptibilities. Nature (2016) 531(7592):110-3. doi: 10.1038/nature16967

74. Ciabatti S, Cammelli S, Frakulli R, Arcelli A, Macchia G, Deodato F, et al. Radiotherapy of Pancreatic Cancer in Older Patients: A Systematic Review. J Geriatr Oncol (2019) 10(4):534-9. doi: 10.1016/j.jgo.2018.09.007

75. Schumacher TN, Schreiber RD. Neoantigens in Cancer Immunotherapy. Science (2015) 348(6230):69-74. doi: 10.1126/science.aaa4971

76. Datar I, Sanmamed MF, Wang J, Henick BS, Choi J, Badri T, et al. Expression Analysis and Significance of PD-1, LAG-3, and TIM-3 in Human Non-Small Cell Lung Cancer Using Spatially Resolved and Multiparametric Single-Cell Analysis. Clin Cancer Res (2019) 25(15):466373. doi: 10.1158/1078-0432.CCR-18-4142

77. Choi M, Kadara H, Zhang J, Parra ER, Rodriguez-Canales J, Gaffney SG, et al. Mutation Profiles in Early-Stage Lung Squamous Cell Carcinoma With Clinical Follow-Up and Correlation With Markers of Immune Function. Ann Oncol (2017) 28(1):83-9. doi: 10.1093/annonc/mdw437

78. McGranahan N, Furness AJS, Rosenthal R, Ramskov S, Lyngaa R, Saini SK, et al. Clonal Neoantigens Elicit T Cell Immunoreactivity and Sensitivity to Immune Checkpoint Blockade. Science (2016) 351(6280):1463-9. doi: 10.1126/science.aaf1490

79. Shi X, Chakraborty P, Chaudhuri A. Unmasking Tumor Heterogeneity and Clonal Evolution by Single-Cell Analysis. J Cancer Metastasis Treat (2018) 4:47. doi: 10.20517/2394-4722.2018.32

80. Turajlic S, Sottoriva A, Graham T, Swanton C. Resolving Genetic Heterogeneity in Cancer. Nat Rev Genet (2019) 20(7):404-16. doi: 10.1038/s41576-019-0114-6

81. Rizvi NA, Hellmann MD, Snyder A, Kvistborg P, Makarov V, Havel JJ, et al. Mutational Landscape Determines Sensitivity to PD-1 Blockade in NonSmall Cell Lung Cancer. Science (2015) 348(6230):124-8. doi: 10.1126/ science.aaa 1348

82. Leung ML, Davis A, Gao R, Casasent A, Wang Y, Sei E, et al. Single-Cell DNA Sequencing Reveals a Late-Dissemination Model in Metastatic Colorectal Cancer. Genome Res (2017) 27(8):1287-99. doi: 10.1101/gr.209973.116

83. Baslan T, Kendall J, Rodgers L, Cox H, Riggs M, Stepansky A, et al. GenomeWide Copy Number Analysis of Single Cells. Nat Protoc (2012) 7(6):102441. doi: 10.1038/nprot.2012.039

84. Darılmaz Yüce G, Ortaç Ersoy E. [Lung Cancer and Epigenetic Modifications]. Tuberk Toraks (2016) 64(2):163-70. doi: 10.5578/tt.10231

85. Duruisseaux M, Esteller M. Lung Cancer Epigenetics: From Knowledge to Applications. Semin Cancer Biol (2018) 51:116-28. doi: 10.1016/ j.semcancer.2017.09.005 
86. Yuan G, Flores NM, Hausmann S, Lofgren SM, Kharchenko V, Angulo-Ibanez M, et al. Elevated NSD3 Histone Methylation Activity Drives Squamous Cell Lung Cancer. Nature (2021) 590(7846):504-8. doi: 10.1038/s41586-020-03170-y

87. Mehta A, Dobersch S, Romero-Olmedo AJ, Barreto G. Epigenetics in Lung Cancer Diagnosis and Therapy. Cancer Metastasis Rev (2015) 34(2):229-41. doi: 10.1007/s10555-015-9563-3

88. Franco F, Jaccard A, Romero P, Yu YR, Ho PC. Metabolic and Epigenetic Regulation of T-Cell Exhaustion. Nat Metab (2020) 2(10):1001-12. doi: 10.1038/s42255-020-00280-9

89. Kommalapati A, Tanvetyanon T. Epigenetic Modulation of Immunotherapy Cofactors to Enhance Tumor Response in Lung Cancer. Hum Vaccines Immunotherapeut (2021) 17(1):51-4. doi: 10.1080/21645515.2020.1764273

90. Cui Z, Cui Y, Gao Y, Jiang T, Zang T, Wang Y. Enhancement and Imputation of Peak Signal Enables Accurate Cell-Type Classification in scATAC-Seq. Front Genet (2021) 12:658352. doi: 10.3389/fgene.2021.658352

91. Ku WL, Nakamura K, Gao W, Cui K, Hu G, Tang Q, et al. Single-Cell Chromatin Immunocleavage Sequencing (Scchic-Seq) to Profile Histone Modification. Nat Methods (2019) 16(4):323-5. doi: 10.1038/s41592-019-0361-7

92. Ramani V, Deng X, Qiu R, Gunderson KL, Steemers FJ, Disteche CM, et al. Massively Multiplex Single-Cell Hi-C. Nat Methods (2017) 14(3):263-6. doi: 10.1038/nmeth. 4155

93. Bartosovic M, Kabbe M, Castelo-Branco G. Single-Cell CUT\&Tag Profiles Histone Modifications and Transcription Factors in Complex Tissues. Nat Biotechnol (2021) 39(7):825-35. doi: 10.1038/s41587-021-00869-9

94. Buenrostro JD, Wu B, Litzenburger UM, Ruff D, Gonzales ML, Snyder MP, et al. Single-Cell Chromatin Accessibility Reveals Principles of Regulatory Variation. Nature (2015) 523(7561):486-90. doi: 10.1038/nature14590

95. Lee D-S, Luo C, Zhou J, Chandran S, Rivkin A, Bartlett A, et al. Simultaneous Profiling of 3D Genome Structure and DNA Methylation in Single Human Cells. Nat Methods (2019) 16(10):999-1006. doi: 10.1038/s41592-019-0547-z

96. Gu H, Raman AT, Wang X, Gaiti F, Chaligne R, Mohammad AW, et al. Smart-RRBS for Single-Cell Methylome and Transcriptome Analysis. Nat Protoc (2021) 16(8):4004-30. doi: 10.1038/s41596-021-00571-9

97. Nigro E, Imperlini E, Scudiero O, Monaco ML, Polito R, Mazzarella G, et al. Differentially Expressed and Activated Proteins Associated With Non Small Cell Lung Cancer Tissues. Respir Res (2015) 16(1):74. doi: 10.1186/s12931015-0234-2

98. Kelly RT. Single-Cell Proteomics: Progress and Prospects. Mol Cell Proteomics (2020) 19(11):1739-48. doi: 10.1074/mcp.R120.002234

99. Rahman AH, Lavin Y, Kobayashi S, Leader A, Merad M. High-Dimensional Single Cell Mapping of Cerium Distribution in the Lung Immune Microenvironment of an Active Smoker. Cytomet B Clin Cytom (2018) 94 (6):941-5. doi: 10.1002/cyto.b.21545

100. Dou M, Clair G, Tsai CF, Xu K, Chrisler WB, Sontag RL, et al. HighThroughput Single Cell Proteomics Enabled by Multiplex Isobaric Labeling in a Nanodroplet Sample Preparation Platform. Anal Chem (2019) 91 (20):13119-27. doi: 10.1021/acs.analchem.9b03349

101. Lin CC, Huang WL, Su WP, Chen HH, Lai WW, Yan JJ, et al. Single Cell Phospho-Specific Flow Cytometry can Detect Dynamic Changes of Phospho-Stat1 Level in Lung Cancer Cells. Cytomet A (2010) 77(11):100819. doi: 10.1002/cyto.a.20965

102. O'Neill LAJ, Pearce EJ. Immunometabolism Governs Dendritic Cell and Macrophage Function. J Exp Med (2016) 213(1):15-23. doi: 10.1084/jem.20151570

103. Weber GF. Metabolism in Cancer Metastasis. Int J Cancer (2016) 138 (9):2061-6. doi: 10.1002/ijc.29839

104. Schmidt DR, Patel R, Kirsch DG, Lewis CA, Vander Heiden MG, Locasale JW. Metabolomics in Cancer Research and Emerging Applications in Clinical Oncology. CA: A Cancer J Clin (2021) 71(4):333-58. doi: 10.3322/ caac. 21670

105. Bergers G, Fendt S-M. The Metabolism of Cancer Cells During Metastasis. Nat Rev Cancer (2021) 21:162-80. doi: 10.1038/s41568-020-00320-2

106. Leone RD, Powell JD. Metabolism of Immune Cells in Cancer. Nat Rev Cancer (2020) 20(9):516-31. doi: 10.1038/s41568-020-0273-y

107. Huang H, Zhou P, Wei J, Long L, Shi H, Dhungana Y, et al. In Vivo CRISPR Screening Reveals Nutrient Signaling Processes Underpinning CD8+ T Cell Fate Decisions. Cell (2021) 184(5):1245-61.e21. doi: 10.1016/j.cell.2021.02.021

108. Zappasodi R, Serganova I, Cohen IJ, Maeda M, Shindo M, Senbabaoglu Y, et al. CTLA-4 Blockade Drives Loss of Treg Stability in Glycolysis-
Low Tumours. Nature (2021) 591(7851):652-8. doi: 10.1038/s41586021-03326-4

109. Shrestha B. Ten Major Future Challenges in Single-Cell Metabolomics, in Single Cell Metabolism: Methods and Protocols. B Shrestha, editor. New York, NY: Springer New York (2020) p. 219-23.

110. Evers TMJ, Hochane M, Tans SJ, Heeren RMA, Semrau S, Nemes P, et al. Deciphering Metabolic Heterogeneity by Single-Cell Analysis. Analytical Chem (2019) 91(21):13314-23. doi: 10.1021/acs.analchem.9b02410

111. Arguello RJ, Combes AJ, Char R, Gigan JP, Baaziz AI, Bousiquot E, et al. SCENITH: A Flow Cytometry-Based Method to Functionally Profile Energy Metabolism With Single-Cell Resolution. Cell Metab (2020) 32(6):1063-.e7. doi: 10.1016/j.cmet.2020.11.007

112. Vodnala SK, Eil R, Kishton RJ, Sukumar M, Yamamoto TN, Ha NH, et al. T Cell Stemness and Dysfunction in Tumors Are Triggered by a Common Mechanism. Science (2019) 363(6434):eaau0135. doi: 10.1126/science.aau0135

113. Depeaux K, Delgoffe GM. Metabolic Barriers to Cancer Immunotherapy. Nat Rev Immunol (2021) 21:785-97. doi: 10.1038/s41577-021-00541-y

114. Sheng N, Li Y, Qian R, Li Y. The Clinical Significance and Biological Function of lncRNA RGMB-AS1 in Hepatocellular Carcinoma. BioMed Pharmacother (2018) 98:577-84. doi: 10.1016/j.biopha.2017.12.067

115. Hu KH, Eichorst JP, McGinnis CS, Patterson DM, Chow ED, Kersten K, et al. ZipSeq: Barcoding for Real-Time Mapping of Single Cell Transcriptomes. Nat Methods (2020) 17(8):833-43. doi: 10.1101/2020.02.04.932988

116. Wu SS, Lee JH, Koo BK. Lineage Tracing: Computational Reconstruction Goes Beyond the Limit of Imaging. Mol Cells (2019) 42(2):104-12. doi: 10.14348/molcells.2019.0006

117. Wagner DE, Weinreb C, Collins ZM, Briggs JA, Megason SG, Klein AM. SingleCell Mapping of Gene Expression Landscapes and Lineage in the Zebrafish Embryo. Science (2018) 360(6392):981-7. doi: 10.1126/science.aar4362

118. Figueres-Oñate M, Sánchez-Villalón M, Sánchez-González R, LópezMascaraque L. Lineage Tracing and Cell Potential of Postnatal Single Progenitor Cells In Vivo. Stem Cell Rep (2019) 13(4):700-12. doi: 10.1016/ j.stemcr.2019.08.010

119. Praktiknjo SD, Obermayer B, Zhu Q, Fang L, Liu H, Quinn H, et al. Tracing Tumorigenesis in a Solid Tumor Model at Single-Cell Resolution. Nat Commun (2020) 11(1):991. doi: 10.1038/s41467-020-14777-0

120. Zepp JA, Zacharias WJ, Frank DB, Cavanaugh CA, Zhou S, Morley MP, et al. Distinct Mesenchymal Lineages and Niches Promote Epithelial Self-Renewal and Myofibrogenesis in the Lung. Cell (2017) 170(6):1134-48.e10. doi: 10.1016/j.cell.2017.07.034

121. Wellenstein MD, de Visser KE. Cancer-Cell-Intrinsic Mechanisms Shaping the Tumor Immune Landscape. Immunity (2018) 48(3):399-416. doi: 10.1016/j.immuni.2018.03.004

122. Wagner DE, Klein AM. Lineage Tracing Meets Single-Cell Omics: Opportunities and Challenges. Nat Rev Genet (2020) 21(7):410-27. doi: 10.1038/s41576-020-0223-2

123. Liu Q, Liu K, Cui G, Huang X, Yao S, Guo W, et al. Lung Regeneration by Multipotent Stem Cells Residing at the Bronchioalveolar-Duct Junction. Nat Genet (2019) 51(4):728-38. doi: 10.1038/s41588-019-0346-6

124. Lein E, Borm LE, Linnarsson S. The Promise of Spatial Transcriptomics for Neuroscience in the Era of Molecular Cell Typing. Science (2017) 358 (6359):64-9. doi: 10.1126/science.aan6827

125. De Bruin EC, McGranahan N, Mitter R, Salm M, Wedge DC, Yates L, et al. Spatial and Temporal Diversity in Genomic Instability Processes Defines Lung Cancer Evolution. Science (2014) 346(6206):251-6. doi: 10.1126/science.1253462

126. Moor AE, Itzkovitz S. Spatial Transcriptomics: Paving the Way for TissueLevel Systems Biology. Curr Opin Biotechnol (2017) 46:126-33. doi: 10.1016/ j.copbio.2017.02.004

127. Baccin C, Al-Sabah J, Velten L, Helbling PM, Grünschläger F, HernándezMalmierca P, et al. Combined Single-Cell and Spatial Transcriptomics Reveal the Molecular, Cellular and Spatial Bone Marrow Niche Organization. Nat Cell Biol (2020) 22(1):38-48. doi: 10.1038/s41556019-0439-6

128. Wang X, Allen WE, Wright MA, Sylwestrak EL, Samusik N, Vesuna S, et al. Three-Dimensional Intact-Tissue Sequencing of Single-Cell Transcriptional States. Science (2018) 361(6400):eaat5691. doi: 10.1126/science.aat5691

129. Kumar MP, Du J, Lagoudas G, Jiao Y, Sawyer A, Drummond DC, et al. Analysis of Single-Cell RNA-Seq Identifies Cell-Cell Communication 
Associated With Tumor Characteristics. Cell Rep (2018) 25(6):1458-68.e4. doi: 10.1016/j.celrep.2018.10.047

130. Zhang L, Mao S, Yao M, Chao N, Yang Y, Ni Y, et al. Spatial transcriptome sequencing revealed spatial trajectory in the Non-Small Cell Lung Carcinoma. bioRxiv (2021) 2021.04.26.441394. doi: 10.1101/2021.04. 26.441394

131. Mascaux C, Angelova M, Vasaturo A, Beane J, Hijazi K, Anthoine G, et al. Immune Evasion Before Tumour Invasion in Early Lung Squamous Carcinogenesis. Nature (2019) 571(7766):570-5. doi: 10.1038/s41586-019$1330-0$

132. Meng L, Jiang X, Liang J, Pan Y, Pan F, Liu D. Postoperative Psychological Stress and Expression of Stress-Related Factors HSP70 and IFN- $\gamma$ in Patients With Early Lung Cancer. Minerva Med (2020). doi: 10.23736/S00264806.20.06658-6

133. Eruslanov EB, Bhojnagarwala PS, Quatromoni JG, Stephen TL, Ranganathan A, Deshpande C, et al. Tumor-Associated Neutrophils Stimulate T Cell Responses in Early-Stage Human Lung Cancer. J Clin Invest (2014) 124 (12):5466-80. doi: 10.1172/JCI77053

134. Laughney AM, Hu J, Campbell NR, Bakhoum SF, Setty M, Lavallee VP, et al. Regenerative Lineages and Immune-Mediated Pruning in Lung Cancer Metastasis. Nat Med (2020) 26(2):259-69. doi: 10.1038/s41591-019-0750-6
135. Beaumont KG, Beaumont MA, Sebra R. Application of Single-Cell Sequencing to Immunotherapy. Urol Clin North Am (2020) 47(4):475-85. doi: 10.1016/j.ucl.2020.07.005

Conflict of Interest: The authors declare that the research was conducted in the absence of any commercial or financial relationships that could be construed as a potential conflict of interest.

Publisher's Note: All claims expressed in this article are solely those of the authors and do not necessarily represent those of their affiliated organizations, or those of the publisher, the editors and the reviewers. Any product that may be evaluated in this article, or claim that may be made by its manufacturer, is not guaranteed or endorsed by the publisher.

Copyright $\odot 2021$ Chen, Liu, Li, Wang, Ren, Wang, Chen and Li. This is an openaccess article distributed under the terms of the Creative Commons Attribution License (CC BY). The use, distribution or reproduction in other forums is permitted, provided the original author(s) and the copyright owner(s) are credited and that the original publication in this journal is cited, in accordance with accepted academic practice. No use, distribution or reproduction is permitted which does not comply with these terms. 